\title{
Impact of emission controls on air quality in Beijing during APEC 2014: lidar ceilometer observations
}

\author{
G. Tang ${ }^{1}$, X. Zhu ${ }^{1}$, B. Hu ${ }^{1}$, J. Xin ${ }^{1}$, L. Wang ${ }^{1}$, C. Münkel ${ }^{2}$, G. Mao ${ }^{3}$, and Y. Wang ${ }^{1}$ \\ ${ }^{1}$ State Key Laboratory of Atmospheric Boundary Layer Physics and Atmospheric Chemistry (LAPC), \\ Institute of Atmospheric Physics, Chinese Academy of Sciences, Beijing 100029, China \\ ${ }^{2}$ Vaisala GmbH, 22607 Hamburg, Germany \\ ${ }^{3}$ Institute of Meteorology and Climate Research (IMK-IFU), Karlsruhe Institute of Technology (KIT), Kreuzeckbahnstr. 19, \\ 82467 Garmisch-Partenkirchen, Germany
}

Correspondence to: Y. Wang (wys@mail.iap.ac.cn)

Received: 30 March 2015 - Published in Atmos. Chem. Phys. Discuss.: 5 May 2015

Revised: 19 October 2015 - Accepted: 1 November 2015 - Published: 13 November 2015

\begin{abstract}
The implementation of emission reductions during the 2014 Asia-Pacific Economic Cooperation (APEC) summit provides a valuable opportunity to study air pollution in Beijing. From 15 October to 30 November 2014, the height of the atmospheric mixing layer and the vertical attenuated backscattering coefficient profiles were observed online using a lidar ceilometer. Compared with fine particulate matter $\left(\mathrm{PM}_{2.5}\right)$ and aerosol optical depth (AOD) data, the attenuated backscattering coefficients measured by the lidar ceilometer were strongly correlated with the $\mathrm{PM}_{2.5}$ concentration and AOD (correlation coefficients of 0.89 and 0.86 , respectively). This result demonstrated the reliability of the vertical distribution of particles measured by the lidar ceilometer. By classifying different degrees of air pollution based on visibility, we found that during the transition period of air pollution, which was affected by transport of southerly flows in the mixing layer, the attenuated backscattering coefficient from 0 to $1500 \mathrm{~m}$ was enhanced by approximately $1.4 \mathrm{Mm}^{-1} \mathrm{sr}^{-1}(140 \%)$. During the polluted period, the attenuated backscattering coefficient from 0 to $300 \mathrm{~m}$ suddenly increased, and the coefficient near the surface peaked (approximately $14 \mathrm{Mm}^{-1} \mathrm{sr}^{-1}$ ); however, the attenuated backscattering coefficient from 300 to $900 \mathrm{~m}$ decreased gradually, and the average value from 0 to $1500 \mathrm{~m}$ decreased by $0.5 \mathrm{Mm}^{-1} \mathrm{sr}^{-1}(20 \%)$. The height of the mixing layer gradually decreased, and the ratio of $\mathrm{CO} / \mathrm{SO}_{2}$ gradually increased, which indicate that the polluted period was dominated by local contribution. Due to the emission reductions during APEC (DAPEC), the concentration of $\mathrm{PM}_{2.5}$ de-
\end{abstract}

creased by 59.2 and $58.9 \%$ and visibility improved by 70.2 and $56.0 \%$ compared to before (BAPEC) and after APEC (AAPEC), respectively. The contribution of regional transport in DAPEC decreased by approximately 36 and $25 \%$, and the local contribution decreased by approximately 48 and $54 \%$ compared to BAPEC and AAPEC, respectively. The most effective method of controlling air pollution in the Beijing area is to reduce regional emissions during the transition period and reduce local emissions during the polluted period.

\section{Introduction}

Aerosols are relatively stable suspensions formed by microliquid and micro-solid particles that are uniformly distributed in the air (Seinfeld and Pandis, 1998). Atmospheric aerosols can directly change the balance and distribution of global radiation by scattering or absorbing sunlight, and they can also affect the formation of clouds and fog (as condensation nuclei) and indirectly affect the global climate (Shine and Forster, 1999; Myhre et al., 2001; IPCC, 2007). Furthermore, atmospheric aerosols are carriers of photochemical reactions and provide good reaction beds for chemical reactions; therefore, they promote the occurrence of atmospheric photochemical reactions (Seinfeld and Pandis, 1998). Because of their small radii and high specific areas, atmospheric aerosols can easily accumulate as hazardous material and can be absorbed by human bodies, where they are deposited in 


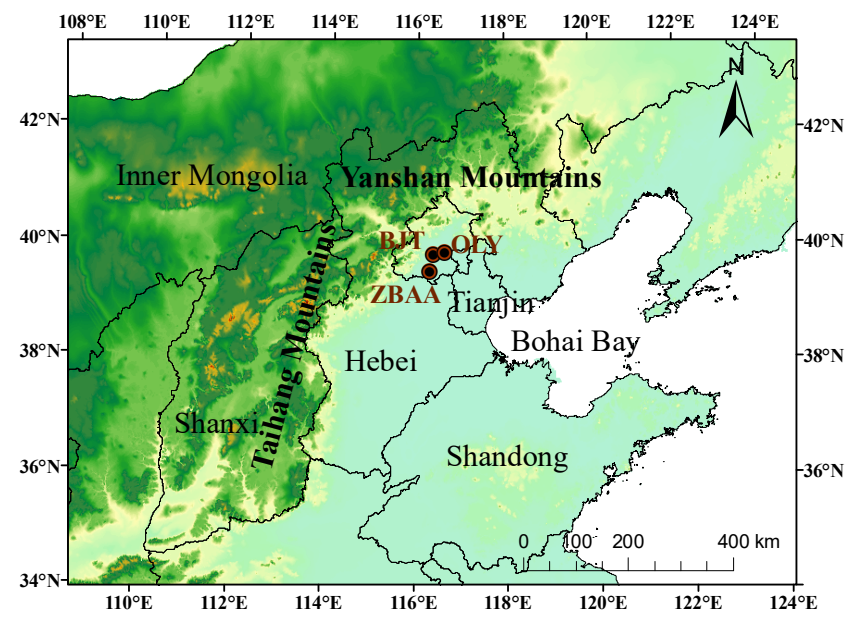

Figure 1. Observation sites and topography over northern China.

the lungs and threaten human health (Englert, 2004; Campbell et al., 2005; Peters, 2005; Auger et al., 2006).

With the rapid economic development of China, the amount of industrial products and the number of vehicles increase year by year, thus leading to an increase of energy consumption (National Bureau of Statistics of China, 2014). The North China Plain region has one of the highest global aerosol concentrations (Lu et al., 2010). Beijing, the economic, political and cultural center of China, is adjacent to the Yanshan Mountains to the north and Taihang Mountains to the west and is on the north boundary of the North China Plain (Fig. 1). This special horseshoe-shaped geographical region provides efficient southerly transport of pollutants to Beijing, which affects air quality (Ding et al., 2005; Xin et al., 2010). In 2012, China promulgated the Air Pollution Prevention and Control Action Plan to prevent and control air pollution, and the details were disseminated in September 2012. The key control region for air pollution is the North China Plain, which contains Beijing, Tianjin and Hebei. The coordinated prevention and control of pollution in this region have been proposed (State council, 2013).

Although coordinated regional prevention and control have been proposed for many years, it is difficult to obtain evidence and quantify the intensity of regional transport solely based on ground observations. Thus, reductions in regional emissions have not been implemented. Previous studies attempted to use air quality models to quantify the intensity and height of regional transport (Wu et al., 2011). However, the vertical gradient of air pollutants was not measured to test the model; therefore, the results are not reliable. Thus, it is of great importance to measure the vertical gradient of air pollutants to quantify the intensity and height of the regional transport.

Studies of the vertical distribution characteristics of atmospheric aerosols include layered observations from meteorological observation towers, mooring boats, airplanes, ground remote sensing and satellites, and such data can be utilized for exploration and measurements of different spatial regions from near the surface to the free atmosphere. Using these observation methods to study the vertical gradient, the effects of sand storms (Zhang et al., 2006; McAuliffe and Ruth, 2013), volcanic eruptions (Emeis et al., 2011), and anthropogenic sources (Tesche et al., 2007; Kamp et al., 2008; Zhang et al., 2009; Hänel et al., 2012; Sun et al., 2013) on the atmospheric environment have been evaluated in several countries. However, such studies in northern China remain at the initial stages. Using the airplane observation method, Zhang et al. (2006) classified the origin of atmospheric aerosols in Beijing and showed that they are primarily affected by sand storms, southerly transport and local emissions. Their airplane data were used to determine the concentration of aerosol particles and vertical distribution characteristics of particle radii in the Beijing area during the periods when atmospheric aerosols are mainly affected by anthropogenic sources. Zhang et al. (2009) also analyzed the causes of vertical aerosol distribution under different meteorological conditions by considering meteorological factors. Guinot et al. (2006) and Sun et al. (2013) used the layered meteorological observation method to show variations in the vertical gradient of air pollutants during periods of heavy pollution. Although the aforementioned studies analyzed the vertical variation of aerosols in the Beijing area, the results are not ideal because they have low resolution, small sample size and low observational height; they are unrepresentative; and they lack evidence for regional transport. In recent years, satellite observations have become increasingly important in investigations of atmospheric aerosol profiles. In addition, satellite observations provide reliable results compared with ground remote sensing (Wu et al., 2014). However, the resolution of the satellite observation method is very low because of short passing time. Therefore, surface remote sensing is the best method to acquire the continuous vertical structure of atmospheric aerosols at high resolution.

The Asia-Pacific Economic Cooperation (APEC) summit was held from 3 to 11 November 2014 in Beijing, and it was important to ensure good air quality to provide for a successful summit. Thus, the governments of Hebei province, Tianjin city, Shanxi province, Inner Mongolia Autonomous Region, and Shandong province cooperated with the government of Beijing to increase the intensity of emission reductions for the entire region of northern China during the APEC summit, and a series of emission reduction methods were conducted. Consequently, more than 460 businesses with high emissions in Beijing were required to stop or limit their production during 3-12 November 2014. The number of private vehicles in operation during the same period was reduced by $50 \%$ through an odd/even-number-plate rule. Further, 9298 enterprises were suspended, 3900 enterprises were ordered to limit production, and more than 40000 construction sites were shut down in all six of the provinces, cities and autonomous region. Additionally, when the heat- 
ing supply began to run extensively after 15 November, there was also a slight difference in emissions in the time periods before and after APEC. Therefore, the implementation of these emission variability methods resulted in significant variations in regional transport and local pollutant contributions.

In this study, a lidar ceilometer was used to determine the mixing-layer height and the attenuated backscattering coefficient before and after APEC (15 October to 30 November 2014). The values for fine particulate matter $\left(\mathrm{PM}_{2.5}\right)$ and aerosol optical depth (AOD) were combined, and the present study tested and compared the attenuated backscattering coefficient measured by the lidar ceilometer from 15 October to 30 November 2014. By applying visibility as an index to classify the degrees of air pollution, the vertical gradients of the attenuated backscattering coefficient were analyzed during multiple pollution episodes to determine the origin of atmospheric pollution for different degrees of air pollution. Afterwards, changes in the attenuated backscattering coefficient profiles before, during and after APEC (BAPEC, DAPEC and AAPEC, respectively) reflect the causes of variation under different pollution conditions and relative contribution of regional transport and local emissions in DAPEC. Finally, three typical pollution episodes were analyzed in BAPEC, DAPEC and AAPEC to show the origin of atmospheric pollution under different pollution conditions in Beijing and the effects of the emission reduction methods in DAPEC. The results strengthen our knowledge of pollution formation and development in the Beijing area and provide a scientific basis for the control of air pollution in Beijing.

\section{Methods}

\subsection{Measurements of attenuated backscattering coefficients}

An observational station (BJT) was built in the Tieta courtyard of the Institute of Atmospheric Physics of the Chinese Academy of Science (west of Jiandemen, Haidian district, Beijing) (Fig. 1). The station was between North Third Ring Road and North Fourth Ring Road, and route G6 was on the east side. The geographic location of the station was $39.97^{\circ} \mathrm{N}, 116.37^{\circ} \mathrm{E}$, and the altitude was $60 \mathrm{~m}$.

The equipment used in this study included an enhanced single-lens lidar ceilometer (CL51, Vaisala). This equipment adopted the strobe laser lidar (laser detection and distance measurement) technique $(910 \mathrm{~nm})$ to measure the atmospheric attenuated backscattering coefficient profiles. The detection distance of the CL51 ceilometer was $15.4 \mathrm{~km}$, and it had a temporal resolution of 6-120 s and vertical resolution of $10 \mathrm{~m}$. Because the height of the atmospheric mixing layer barely exceeded $4 \mathrm{~km}$ and the concentration of aerosols in the free atmosphere above the mixing layer is low in the Beijing area, high detection distance was not necessary to study the air pollution in this area. To strengthen the echo signals and reduce detection noise, the detection height of the ceilometer was reduced by half to $7.7 \mathrm{~km}$. Additional data were obtained to smooth the noise of detection signals by setting the temporal resolution of detection to $16 \mathrm{~s}$. To filter the noise of the observed data, $240 \mathrm{~m}$ vertical, $1200 \mathrm{~s}$ time smoothly averaging was applied by BL-VIEW software before analyses (Münkel et al., 2007).

\subsection{Evaluation method of attenuated backscattering coefficients}

Although aerosol concentration cannot be measured directly by a ceilometer (Wiegner et al., 2014), the attenuated backscattering coefficient is a good indicator of the aerosol stratification. However, uncertainties might occur in the attenuated backscattering coefficients measured by the lidar ceilometer, especially above the boundary layer, where the aerosol concentration is low (Jin et al., 2015). In addition, the attenuated backscattering coefficients measured in the spectral region of $910 \mathrm{~nm}$ are influenced by water vapor absorption, and the strength of the influence can be highly variable in time and space (Wiegner and Gasteiger, 2015). Therefore, the representativeness of the attenuated backscattering coefficient must be evaluated by comparison with other observations, and a good relationship indicates that the influence of water vapor absorption is negligible.

To evaluate the atmospheric attenuated backscattering coefficients measured by the lidar ceilometer, two methods based on the near-surface $\mathrm{PM}_{2.5}$ concentration and AOD column data were adopted in this study. The reliability of measured results based on calibration of the near-surface attenuated backscattering coefficients was evaluated by comparing the near-surface $\mathrm{PM}_{2.5}$ concentrations and near-surface atmospheric attenuated backscattering coefficients. Observational $\mathrm{PM}_{2.5}$ data were downloaded from the Chinese Environmental Protection Administration website (http://www. zhb.gov.cn/), and observational data at the Olympic center (OLY), which was the closest landmark to the observational station, were chosen for comparison (Fig. 1). The AOD data were measured using the MICROTOPS II heliograph at BJT station (Fig. 1) when the weather conditions were sunny and partly cloudy. Each measurement was repeated three to five times, and the average value was used as the mean value at each time step. Because the waveband of the heliograph is different from the observational range of the lidar ceilometer, the AOD at $910 \mathrm{~nm}$, which is consistent with the wavelength of the lidar ceilometer, was derived from the measured AOD at $1020 \mathrm{~nm}$ using the heliograph and wavelength indices of four wave bands. The derivation method was based on Eq. (1), where $\alpha$ is the wavelength index between 340 and $675 \mathrm{~nm}$, and $\tau$ is the AOD:

$\ln \alpha=\frac{\ln \tau(1020 \mathrm{~nm})-\ln \tau(910 \mathrm{~nm})}{\ln 1020-\ln 910}$. 


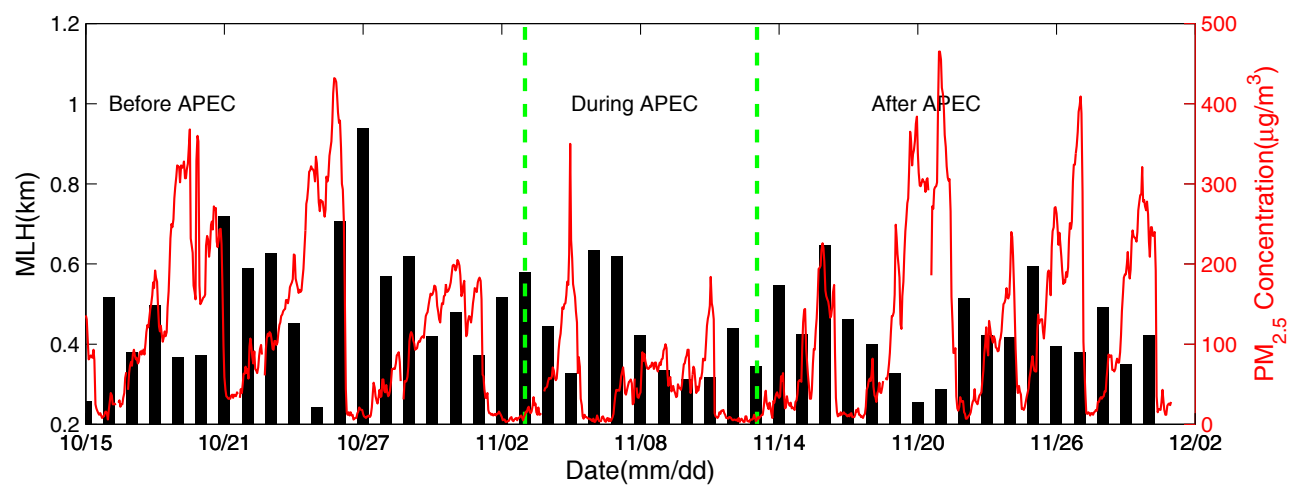

Figure 2. $\mathrm{PM}_{2.5}$ concentrations and mixing-layer heights vs. time from 15 October to 30 November 2014.

\subsection{Calculation of mixing-layer height}

Because the particle lifetimes are long and range from several days to tens of days, the distribution of particle concentrations in the atmospheric mixing layer is more uniform than that of gas-phase pollutants (Seinfeld, and Pandis, 1998). In addition, huge differences in the concentrations of particles are observed between the mixing layer and free atmosphere. The profile of attenuated backscattering coefficients in the atmosphere can be analyzed to determine the location of sudden changes caused by variations in the attenuated backscattering coefficients, which is at the top of the atmospheric mixing layer. The lidar ceilometer is inexpensive and convenient and has been widely applied in observations of the mixing-layer height (Sicard et al., 2006; Münkel et al., 2007; McKendry et al., 2009; Emeis et al., 2012; Yang et al., 2013; Pandolfi et al., 2013; Schween et al., 2014; Scarino et al., 2014). In this study, the gradient method was used to identify the mixing-layer height, and maximum negative gradient value $(-\mathrm{d} \beta / \mathrm{d} x)$ of the attenuated backscattering coefficient profile was at the top of the mixing layer (Michael et al., 2006; Emeis et al., 2012). Because the data are easily affected by noise and interference from the aerosol layering structure, time or space must be smoothly averaged before the gradient method can be used to calculate the mixing-layer height from the profile data (Münkel et al., 2007).

\subsection{Other data}

Because Beijing has a low concentration of industry and a large amount of vehicle traffic, the emissions of $\mathrm{SO}_{2}$ are low, while the emissions of $\mathrm{CO}$ are high. Thus, the ratio of $\mathrm{CO}$ to $\mathrm{SO}_{2}$ may provide a partial indication of the origin of atmospheric pollutants. The $\mathrm{CO}$ and $\mathrm{SO}_{2}$ data at OLY station published by the Chinese Environment Protection Administration were also used to help analyze the origin of atmospheric pollutants (Fig. 1). The observational data were downloaded from the live-updated website published by the Chinese Environment Protection Administration (http://www.zhb.gov.cn/).
Visibility was measured at BJT station using a Belfort Model 6000 visibility sensor to characterize the degree of atmospheric pollution during this period. In addition, to understand the transport characteristics of different degrees of atmospheric pollution, wind speed and direction vertical profile data were obtained from the international standard weather station at Beijing Capital International Airport (ID: ZBAA) (Fig. 1). The meteorological sounding profile data were measured twice a day at 08:00 and 20:00 LT at the ZBAA station.

\section{Results and discussion}

\subsection{Overview of air pollution}

During the summit, a number of controls were adopted to guarantee good air quality in Beijing. To understand the pollution variation tendency during this period, the $\mathrm{PM}_{2.5}$ concentration was plotted against time using the hourly $\mathrm{PM}_{2.5}$ concentration data from 15 October to 30 November (Fig. 2). The observation period lasted for 47 days, and nine poor-airquality episodes were observed, which lasted for 5.2 days on average. During each pollution episode, the $\mathrm{PM}_{2.5}$ concentration was characterized as "slowly accumulating and rapidly disappearing". At the transition stage during each pollution episode, the pollutant concentration increased. After reaching the maximum value, the pollutant concentration plateaued for 1-2 days and then rapidly decreased, which usually lasted for 4 to 6 days from the beginning of the pollution episode to the end. This result is consistent with previous studies (Jia et al., 2008).

A statistical analysis of the ground concentrations of $\mathrm{PM}_{2.5}$ and heights of the mixing layers at the same time showed that the average $\mathrm{PM}_{2.5}$ concentration decreased from 158.9 to $67.9 \mathrm{\mu g} \mathrm{m}^{-3}$, with mixing-layer heights rising from 0 to $1000 \mathrm{~m}$. When mixing-layer heights rose above $1200 \mathrm{~m}$, the $\mathrm{PM}_{2.5}$ concentration suddenly decreased (lower than $35 \mathrm{\mu g} \mathrm{m}^{-3}$ ) and did not vary with increasing height of the mixing layer (Fig. 3). Thus, when the mixing layer was 


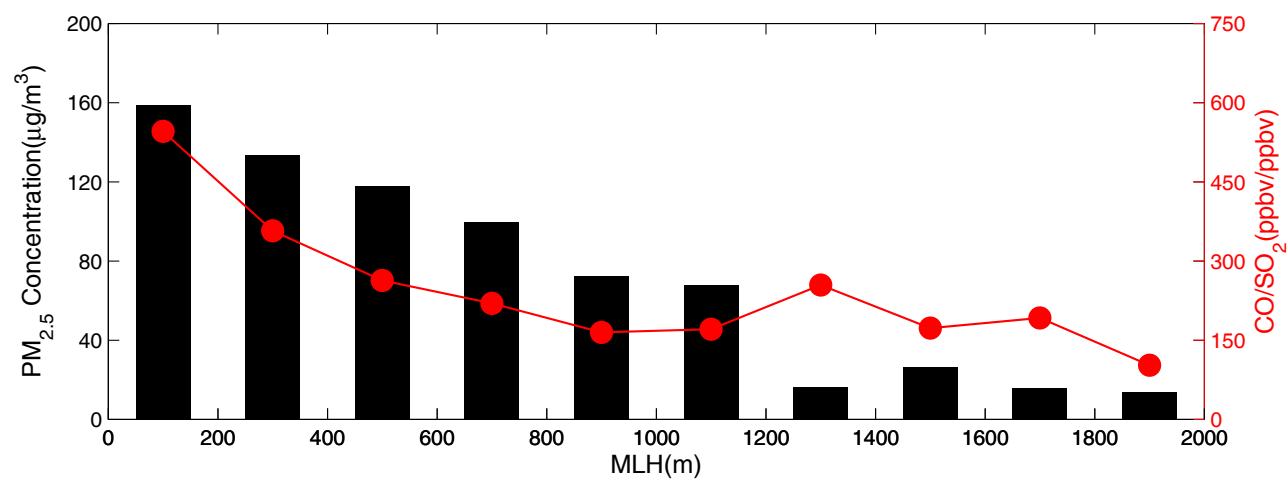

Figure 3. $\mathrm{PM}_{2.5}$ concentrations and $\mathrm{CO} / \mathrm{SO}_{2}$ ratios of the mixing layer at different heights.
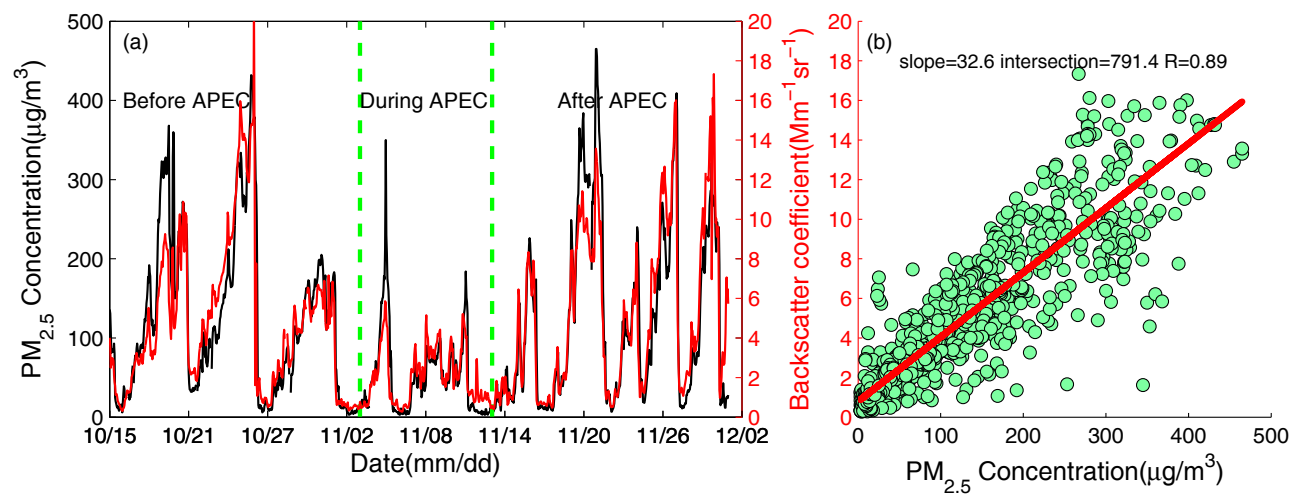

Figure 4. $\mathrm{PM}_{2.5}$ concentrations and attenuated backscattering coefficients vs. time (a) and their correlations (b) from 15 October to 30 November 2014.

lower than $1000 \mathrm{~m}$, the $\mathrm{PM}_{2.5}$ concentration was negatively correlated with the mixing-layer height; when the mixing layer was above $1000 \mathrm{~m}$, the air was of good quality and the negative correlation between the $\mathrm{PM}_{2.5}$ concentration and mixing-layer height disappeared. Therefore, increased pollution during each pollution episode gradually led to the accumulation of $\mathrm{PM}_{2.5}$ above $60 \mu \mathrm{g} \mathrm{m}^{-3}$, and the corresponding mixing-layer heights were all below $1000 \mathrm{~m}$. This result indicates that the vertical diffusion capability of the atmosphere is weak, and atmospheric pollution in Beijing may be enhanced by local emissions. Because the level of industry and coal pollution is low and the number of vehicles is high in Beijing, the ratio of $\mathrm{CO} / \mathrm{SO}_{2}$ can reflect the contribution of local emissions to air pollution, with higher ratios indicating higher local contributions. The ratios of $\mathrm{CO} / \mathrm{SO}_{2}$ show that, with decreasing mixing-layer height, the ratio of $\mathrm{CO} / \mathrm{SO}_{2}$ gradually increased (Fig. 3). This result also suggests that the amount of pollutants transported from other regions gradually decreases while the local contribution gradually increases with increasing pollution.

\subsection{Characteristics of attenuated backscattering coefficients}

\subsubsection{Evaluation of attenuated backscattering coefficients}

Because the vertical distribution of atmospheric pollutants in the convective layer can better represent the evolution characteristics of pollution, the $\mathrm{PM}_{2.5}$ and AOD data observed during this time period were used to compare the near-surface atmospheric attenuated backscattering coefficient and $0-4500 \mathrm{~m}$ column attenuated backscattering coefficient, and the results could be used to evaluate the attenuated backscattering coefficient profile measured by the lidar ceilometer, helping us to better understand the vertical structure of atmospheric pollution.

The overlap of the laser beam of the ceilometer and its receiver field of view is smaller than 1 in the near range. Therefore, the attenuated backscattering coefficient values at a height of $100 \mathrm{~m}$ were chosen for comparison with the nearsurface $\mathrm{PM}_{2.5}$ concentration. The correlation showed that the variations were generally consistent besides differences during several peak periods (Fig. 4a), which indicates that the attenuated backscattering coefficients at $100 \mathrm{~m}$ and corre- 
sponding $\mathrm{PM}_{2.5}$ concentrations were significantly positively correlated $(R=0.89)$ (Fig. $4 b)$. For the column concentration, $4500 \mathrm{~m}$ can generally cover the entire mixing layer; therefore, the interference of cloud layers from 0 to $4500 \mathrm{~m}$ was manually removed, the atmospheric attenuated backscattering coefficients were integrated in this region, and the values were compared with AOD. The results showed that AOD varied directly with the integrated attenuated backscattering coefficient of the atmospheric column (Fig. 5a), and the positive correlation coefficient was as high as 0.86 (Fig. 5b).

It is noteworthy that any comparison with other parameters (PM or AOD) cannot lead to full agreement as long as we cannot quantify the water vapor effect (Wiegner and Gasteiger, 2015). Even so, the significant correlations between the attenuated backscattering coefficients and concentrations of $\mathrm{PM}_{2.5}$ and the AOD showed that the vertical attenuated backscattering coefficient profile measured by the lidar ceilometer could accurately represent the vertical distribution of atmospheric aerosols in Beijing.

\subsubsection{Vertical distribution of attenuated backscattering coefficients}

According to the average vertical gradient of the attenuated backscattering coefficients during the period of observation, we found clear differences between the attenuated backscattering coefficients, with the highest values near the surface and average values reaching $4.5 \mathrm{Mm}^{-1} \mathrm{sr}^{-1}$ (Fig. 6). The vertical lapse rate of the attenuated backscattering coefficients for layers from 0 to $200 \mathrm{~m}$ was small, and the attenuated backscattering coefficients showed limited variation; however, the vertical lapse rate above $200 \mathrm{~m}$ increased and the attenuated backscattering coefficients significantly decreased. After reaching the maximum value at the height of 400 to $800 \mathrm{~m}$, the vertical lapse rate began to decrease gradually. Above $1000 \mathrm{~m}$, the attenuated backscattering coefficient was below $0.65 \mathrm{Mm}^{-1} \mathrm{sr}^{-1}$; at approximately $2000 \mathrm{~m}$, the coefficient was lower than $0.1 \mathrm{Mm}^{-1} \mathrm{sr}^{-1}$. A vertical gradient with high values below and low values above is consistent with the characteristics of vertical gradient in other cities and regions (Tesche et al., 2007; Zhang et al., 2009; Liu et al., 2012; Cao et al., 2013; McAuliffe and Ruth, 2013), although it is different from those regions that are severely affected by regional transport (Noh et al., 2007). Thus, the gradual declining trend in the attenuated backscattering coefficient from near the surface to the upper boundary layer also indicates that the main sources of atmospheric aerosols are from the near-surface layers in Beijing.

\subsubsection{Attenuated backscattering coefficients under different pollution conditions}

Although the main sources of atmospheric aerosols occur in the near-surface layers, fine particles may originate from different locations for the different degrees of pollution of each pollution episode. To analyze the origin of air pollution, visibility was used as an index to indicate the degree of air pollution and applied in the analysis of the vertical gradient profile of the attenuated backscattering coefficients under different visibility conditions (Fig. 7). When the visibility was above $40 \mathrm{~km}$, small differences occurred in the vertical gradients of the attenuated backscattering coefficients from the ground to $1.5 \mathrm{~km}$, and the corresponding attenuated backscattering coefficients were all below $2 \mathrm{Mm}^{-1} \mathrm{sr}^{-1}$. With decreasing visibility, the attenuated backscattering coefficients increased to varying degrees from the ground to $1.0 \mathrm{~km}$. The near-surface layer presented a 2.1 -fold increase from 2.4 to $7.4 \mathrm{Mm}^{-1} \mathrm{sr}^{-1}$ when the visibility decreased from 20 to $4 \mathrm{~km}$, and the mean attenuated backscattering coefficient from 0 to $1500 \mathrm{~m}$ presented a 1.4-fold increase from 1 to $2.4 \mathrm{Mm}^{-1} \mathrm{sr}^{-1}$. In addition, the highly polluted region shifted from $0-300$ to $0-900 \mathrm{~m}$, indicating that transport in the upper boundary layer played an important role from the clear period to the transition period with medium haze. When the visibility decreased from 4 to $1 \mathrm{~km}$, the attenuated backscatter coefficient near the surface varied from 7.4 to $14 \mathrm{Mm}^{-1} \mathrm{sr}^{-1}$. However, the mean attenuated backscattering coefficient from 0 to $1500 \mathrm{~m}$ significantly decreased from 2.4 to $1.9 \mathrm{Mm}^{-1} \mathrm{sr}^{-1}$ (approximately $20 \%$ ). The attenuated backscattering coefficient from 300 to $900 \mathrm{~m}$ significantly decreased, and the variation at approximately $450 \mathrm{~m}$ reached the maximum value (decreasing approximately $4 \mathrm{Mm}^{-1} \mathrm{sr}^{-1}$ ), resulting in a sudden shift of the near-surface high-concentration region from $0-900 \mathrm{~m}$ to 0 $300 \mathrm{~m}$. The significant decrease in the mean column concentration differed from the rapid increase of the near-surface concentration. Such a phenomenon is primarily caused by the weakened transport capability of the atmosphere during heavy haze, which results in decreased concentrations in the space from 300 to $900 \mathrm{~m}$, and the increased contributions of local pollutants lead to a sudden increase of pollutant concentrations. Thus, during the transition period of air pollution, regional transport plays an important role, and within 0 to $600 \mathrm{~m}$ it is characterized by strong regional transport. During the polluted period, local emissions are the most important factor and determine the accumulation rate of pollutants and pollution episode intensity.

\subsection{Impact of emission controls during APEC}

To evaluate the effectiveness of the emission reduction strategies during APEC, the observation period was divided into three parts: BAPEC (15 October to 2 November), DAPEC (3 to 12 November) and AAPEC (13 to 30 November). A statistical analysis of the $\mathrm{PM}_{2.5}$ concentration during these three time periods (Table 1) showed that the $\mathrm{PM}_{2.5}$ concentrations in BAPEC, DAPEC and AAPEC were 126.8, 51.5 and $125.2 \mu \mathrm{g} \mathrm{m}^{-3}$, respectively. Compared with BAPEC and AAPEC, the $\mathrm{PM}_{2.5}$ concentration in DAPEC was decreased by approximately $60 \%$. Correspondingly, the visibility was 

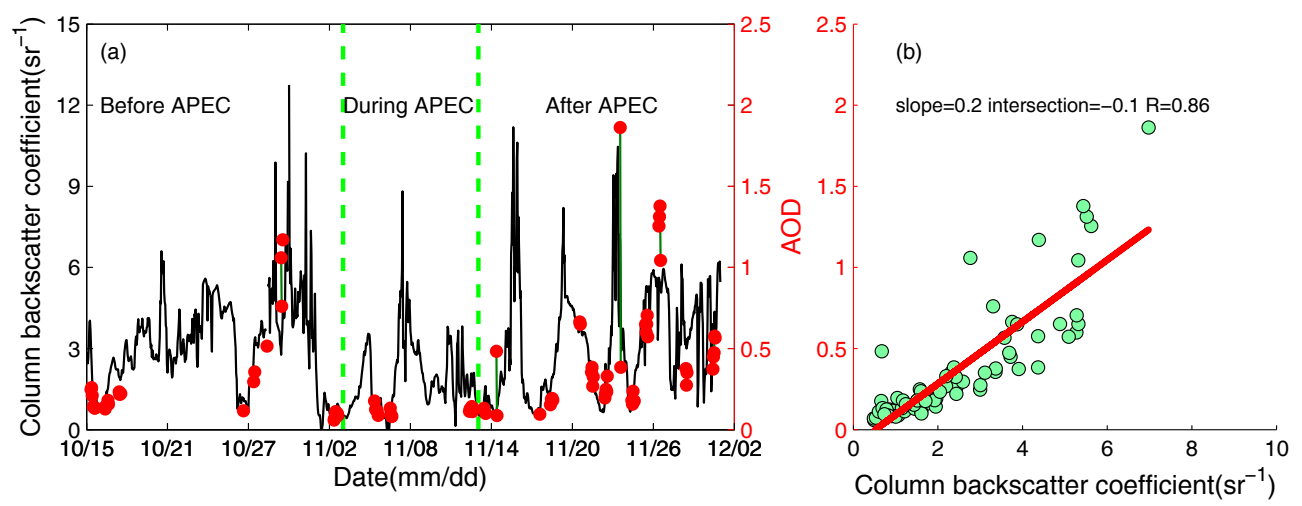

Figure 5. AOD values and 0-4500 m column attenuated backscattering coefficient vs. time (a) and their correlations (b).

Table 1. Meteorological conditions and atmospheric particle concentrations during BAPEC, DAPEC and AAPEC.

\begin{tabular}{lrrrrr}
\hline & $\begin{array}{r}\text { WS } \\
\left(\mathrm{m} \mathrm{s}^{-1}\right)\end{array}$ & $\begin{array}{r}\text { MLH } \\
(\mathrm{m})\end{array}$ & $\begin{array}{r}\text { Ventilation } \\
\text { coefficient }\left(\mathrm{m}^{2} \mathrm{~s}^{-1}\right)\end{array}$ & $\begin{array}{r}\text { Visibility } \\
(\mathrm{km})\end{array}$ & $\begin{array}{r}\mathrm{PM}_{2.5} \\
\left(\mu \mathrm{g} \mathrm{m}^{-3}\right)\end{array}$ \\
\hline BAPEC & 2.4 & 502.3 & 1208.3 & 17.5 & 126.8 \\
DAPEC & 3.1 & 452.8 & 1400.0 & 29.8 & 51.5 \\
AAPEC & 2.6 & 423.9 & 1085.9 & 19.1 & 125.2 \\
\hline
\end{tabular}

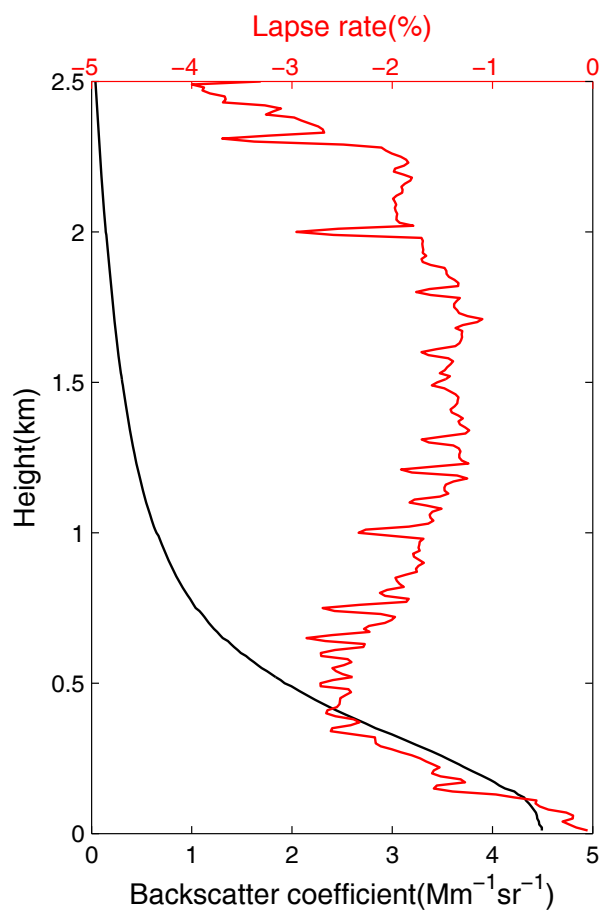

Figure 6. The vertical attenuated backscattering coefficient profile and the lapse rate.

increased from $17.5 \mathrm{~km}$ in BAPEC and $19.1 \mathrm{~km}$ in AAPEC to $29.8 \mathrm{~km}$ in DAPEC, which is an increase of approximately $60 \%$. To evaluate the diffusion capability of the atmosphere during these three periods of time, the corresponding wind speeds and mixing-layer heights were calculated. The wind speeds in BAPEC, DAPEC, and AAPEC were 2.4, 3.1 and $2.6 \mathrm{~m} \mathrm{~s}^{-1}$, respectively, and the mixing-layer heights were 502.3, 452.8 and $423.9 \mathrm{~m}$, respectively. Because wind speeds and mixing-layer heights can represent atmospheric diffusion capacity in the horizontal and vertical directions, respectively, the ventilation coefficient (wind speed multiplied by the mixing-layer height) was used as an index to evaluate the total diffusion capacity of the atmosphere. The ventilation coefficients in BAPEC, DAPEC, and AAPEC were 1208.3, 1400.0 and $1085.9 \mathrm{~m}^{2} \mathrm{~s}^{-1}$, respectively. Thus, the diffusion capability of the atmosphere was best in DAPEC, but the variation magnitude was far below the decreased magnitude of the $\mathrm{PM}_{2.5}$, which indicates that coordinated regional emission reductions might have caused the significant decrease in $\mathrm{PM}_{2.5}$ concentration because of the similar meteorological conditions during these three periods.

The results in Sect. 3.1 and 3.2 show that $\mathrm{PM}_{2.5}$ originates from different sources when the degree of pollution differs. To identify the vertical gradient variations under different pollution conditions in BAPEC, DAPEC and AAPEC, the $\mathrm{PM}_{2.5}$ concentration was divided as follows: 50, 50-100 and $>100 \mu \mathrm{g} \mathrm{m}^{-3}$, which represented the clean period, transition period and polluted period, respectively. The vertical gradient variations of the atmospheric attenuated backscattering coefficients under the three different pollution concentrations were statistically analyzed to obtain the attenuated backscattering coefficient profile plots for the three periods (Fig. 8).

During the clean period, the attenuated backscattering coefficients for BAPEC, DAPEC, and AAPEC from 0 to 

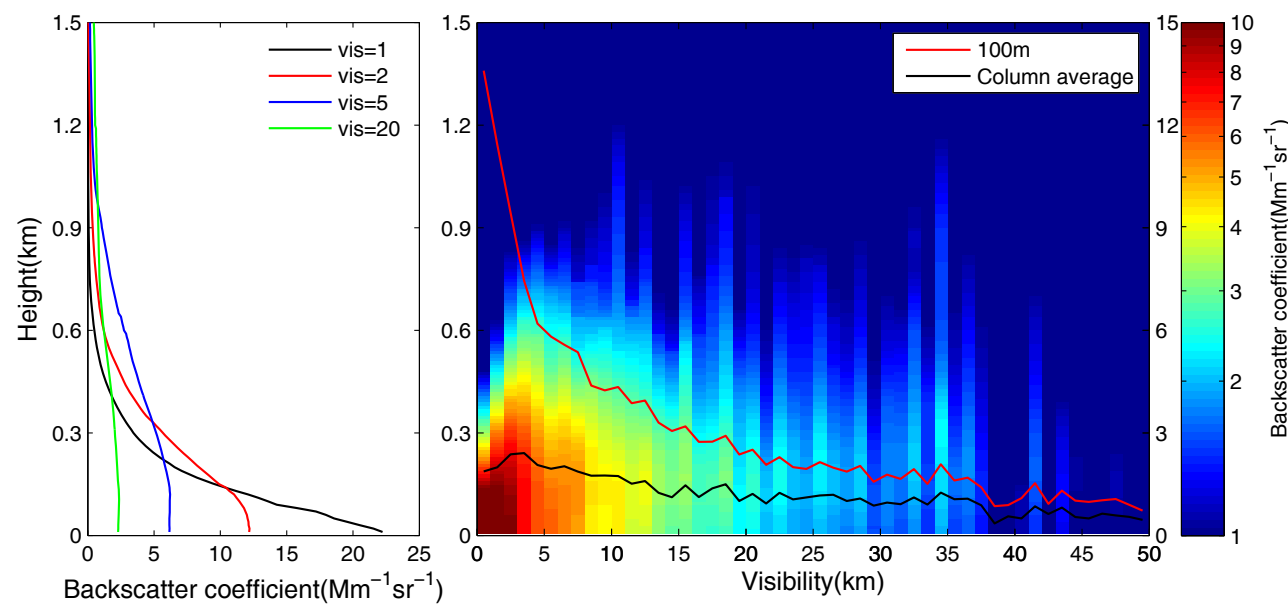

Figure 7. The vertical gradient of attenuated backscattering coefficients under different visibility conditions.
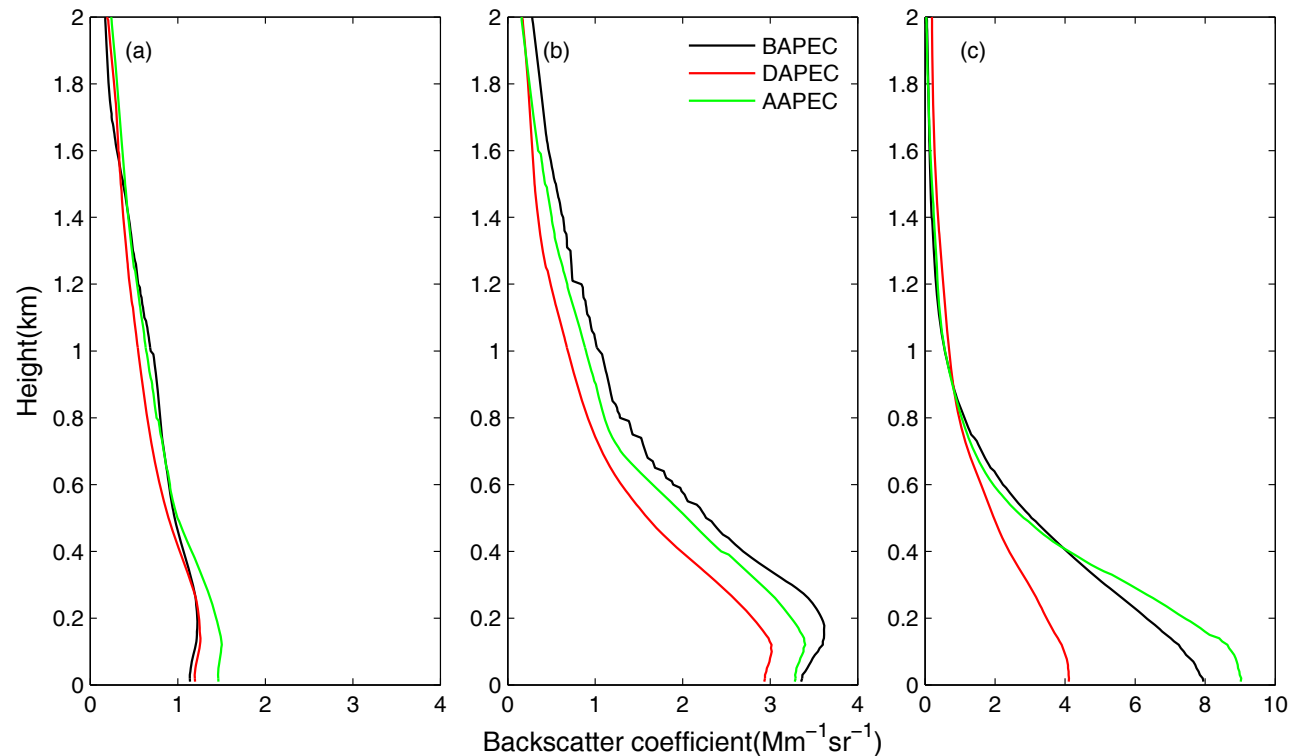

Figure 8. Attenuated backscattering profiles under different air pollution conditions during BAPEC, DAPEC and AAPEC: (a) PM < $50 \mu \mathrm{g} \mathrm{m}^{-3}$, (b) $50 \mu \mathrm{g} \mathrm{m}^{-3}<\mathrm{PM}<100 \mu \mathrm{g} \mathrm{m}^{-3}$, (c) $\mathrm{PM}>100 \mu \mathrm{g} \mathrm{m}^{-3}$.

$2000 \mathrm{~m}$ were similar, and the coefficients for near the surface were all below $1.5 \mathrm{Mm}^{-1} \mathrm{sr}^{-1}$ (Fig. 8a). The nearsurface attenuated backscattering coefficients in AAPEC were $0.3 \mathrm{Mm}^{-1} \mathrm{sr}^{-1}$ higher than those during other periods because of widespread heating after 15 November. The variation magnitude was approximately $20 \%$.

Because of the important effect of regional transport from 0 to $1000 \mathrm{~m}$, the attenuated backscattering coefficients were all higher during the transition period compared with the clean period for BAPEC, DAPEC, and AAPEC, with 1.2to 3-fold changes at different heights (Fig. 8b). Interestingly, compared with BAPEC and AAPEC, greater decreases in the coefficients occurred in DAPEC with increasing height, and at $1000 \mathrm{~m}$ the value was approximately 35 and $25 \%$ lower compared with that of BAPEC and AAPEC, respectively. The smallest decrease of the attenuated backscattering coefficients occurred near the surface at only $10 \%$. The decreased pollutant concentration in the upper boundary layer relative to near the surface showed that regional transport was an important contributor to air pollution in Beijing during the transition period. Considering the dominant effect of regional transport during this period and southerly flow transport in the lower atmosphere within 300 to $900 \mathrm{~m}$, the mean attenuated backscattering coefficients in DAPEC, BAPEC, and AAPEC were calculated to eliminate the effect of local emission. The results showed that the attenuated backscattering coefficient for DAPEC decreased by 36 and $25 \%$ relative to BAPEC and AAPEC, respectively, which indicate that 
the contribution of regional transport to atmospheric aerosols in Beijing decreased by approximately 36 and $25 \%$, respectively.

Compared with the transition period, the near-surface attenuated backscattering coefficients for DAPEC, AAPEC and BAPEC were all greatly enhanced during the heavypollution stage and began to decrease at 600 to $1000 \mathrm{~m}$. The near-surface attenuated backscattering coefficients in BAPEC and AAPEC exceeded $8 \mathrm{Mm}^{-1} \mathrm{sr}^{-1}$, which was approximately twice the variation that occurred in the transition period. The near-surface attenuated backscattering coefficient during the DAPEC polluted period was only $4 \mathrm{Mm}^{-1} \mathrm{sr}^{-1}$, and the increase compared to the transition period was $25 \%$. Compared with BAPEC and AAPEC, the attenuated backscattering coefficients in DAPEC in the space from 0 to $2000 \mathrm{~m}$ were decreased by 0 to $48 \%$ and 0 to $54 \%$, respectively, and the near-surface attenuated backscattering coefficients showed the greatest decrease at 48 and $54 \%$, respectively. With increased height, the decreasing magnitude of the attenuated backscattering coefficients decreased gradually. The higher decreasing magnitude near the surface relative to the upper boundary layer indicates that local emission contributed significantly to air pollution during the polluted period. Considering the dominant role of local emissions during the polluted period and using the near-surface attenuated backscattering coefficient as a baseline, the significant decreases in DAPEC relative to BAPEC and AAPEC indicate that the contribution of local emissions decreased by 48 and $54 \%$, respectively.

Although a number of air pollution controls were implemented in DAPEC, the increased heat supply was the only difference between BAPEC and AAPEC. To evaluate the effect of heat supply on air pollution during the heavy-haze periods in Beijing, the near-surface attenuated backscattering coefficients in BAPEC and AAPEC were compared, and the result showed that they were 1.1-fold higher in AAPEC than BAPEC, which indicates that the contribution from the heat supply to atmospheric aerosols in Beijing is approximately $10 \%$ during the polluted period.

Based on the above discussion, three conclusions can be drawn: (1) the regional transport in DAPEC decreased by 25 and $36 \%$ compared with BAPEC and AAPEC, respectively; (2) the contribution of local emissions in DAPEC decreased by 48 and $54 \%$ compared with BAPEC and AAPEC, respectively; and (3) the contribution of the local heat supply to atmospheric aerosols in Beijing was approximately $10 \%$ during the polluted period. Although the quantitative contributions of local and regional areas are given, these are still rough estimates for different episodes. Detailed contributions of local and regional sources over northern China still need further investigation, and additional observational and modeling studies (although beyond the scope of the present analysis) are suggested for further work.

\subsection{Characteristics of heavy-pollution episodes}

To predict the occurrence and development of air pollution under different pollution conditions in Beijing more precisely, the atmospheric attenuated backscattering coefficients; mixing-layer height; ratio of $\mathrm{CO}$ to $\mathrm{SO}_{2}$ during BAPEC, DAPEC, and AAPEC; and backscattering profile with wind vectors during typical periods (Figs. 9-14) were evaluated in a time-series plot to investigate the characteristics and the causes of the attenuated backscattering coefficients under different pollution conditions at different heights.

The heavy-pollution episodes in BAPEC and AAPEC (Figs. 9, 10, 13 and 14) showed that during the transition periods (21-23 October and 17-18 November) southerly flow resulted in increased mixing-layer height and a gradual increase of the atmospheric attenuated backscattering coefficient from near the surface $(100 \mathrm{~m})$ to the upper boundary layer (300 to $900 \mathrm{~m}$ ). From 300 to $800 \mathrm{~m}$, the effect of the southerly flow was significant, and the pollutant concentration rapidly increased. However, during the polluted periods (23-25 October and 19-20 November), the southerly flow disappeared. Thus, the mixing-layer height decreased because of the westerly and northerly flows, and the attenuated backscattering coefficient of the upper boundary layer began to decrease. The reduction in mixing-layer height and relatively low wind speed promoted an increase in near-surface pollutants, which quantitatively accumulated during the polluted periods. When cold, dry air masses go through Beijing, the attenuated backscattering coefficient and $\mathrm{CO} / \mathrm{SO}_{2}$ ratio in the lower and upper air both rapidly decreased with the rapidly increased mixing-layer height, and the $\mathrm{PM}_{2.5}$ in the atmosphere was significantly decreased. Subsequently, the evolution of a pollutant episode was completed.

Although the mixing-layer height gradually decreased, the "slow accumulation and rapid disappearance" characteristics of the $\mathrm{PM}_{2.5}$ concentration, which were obvious in BAPEC and AAPEC, were not clear in the pollution episode in DAPEC (6-11 October). In addition, variations in the $\mathrm{PM}_{2.5}$ concentration and atmospheric attenuated backscattering coefficient appeared as zigzag shapes, and accumulation and disappearance alternated (Fig. 12). During the transition stage in DAPEC, the variations of air pollutants were similar to those of BAPEC and AAPEC. Because of the effect of the southerly flow, the simultaneous increase in the space from 0 to $900 \mathrm{~m}$ that occurred in BAPEC and AAPEC also occurred in DAPEC (Figs. 11 and 12). In addition, the ratio of $\mathrm{CO}$ to $\mathrm{SO}_{2}$ was low, indicating that regional transport was dominant during this period. During the polluted period, the attenuated backscattering coefficient of the upper boundary layer in DAPEC significantly decreases because of the disappearance of westerly jet flows, which is consistent with what occurred in BAPEC and AAPEC. However, the near-surface attenuated backscattering coefficient did not show a sharp increase (up or down), and the $\mathrm{CO} / \mathrm{SO}_{2}$ ratio did not increase 


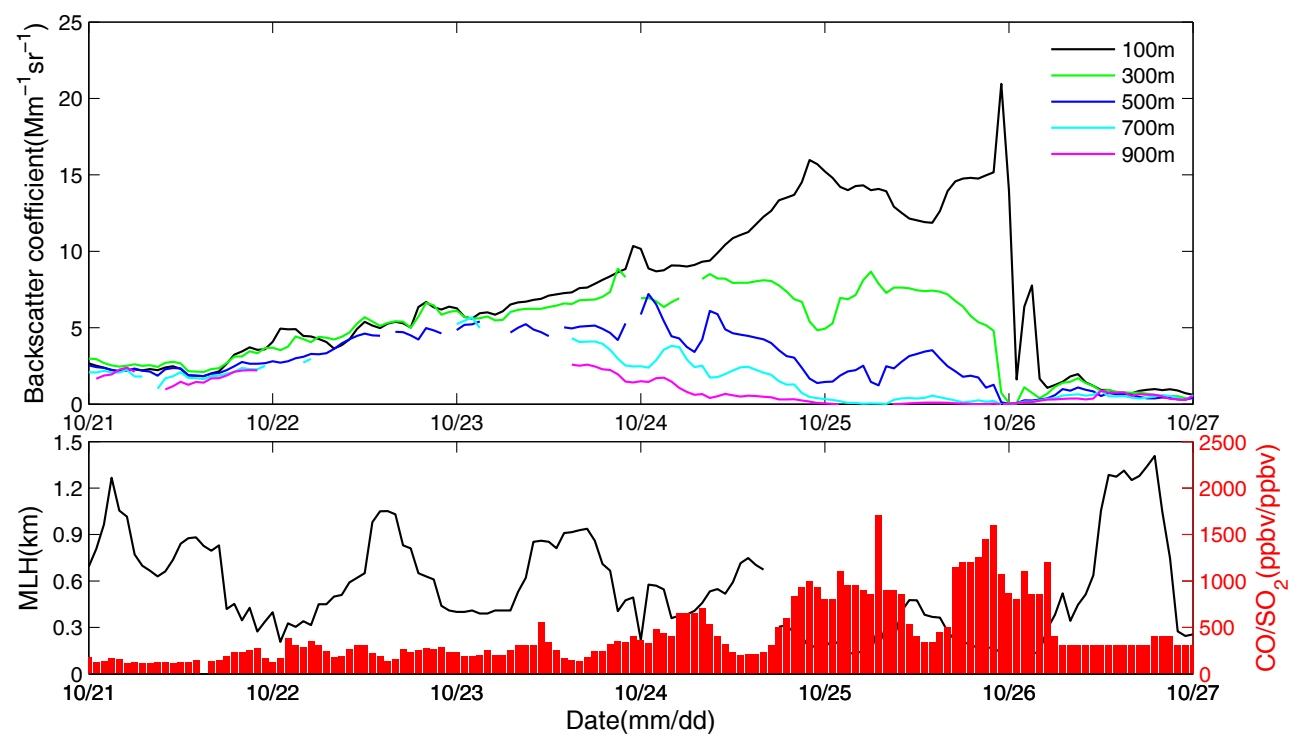

Figure 9. Attenuated backscattering coefficients at different heights and near-surface $\mathrm{CO} / \mathrm{SO}_{2}$ ratios from 21 to 26 October.
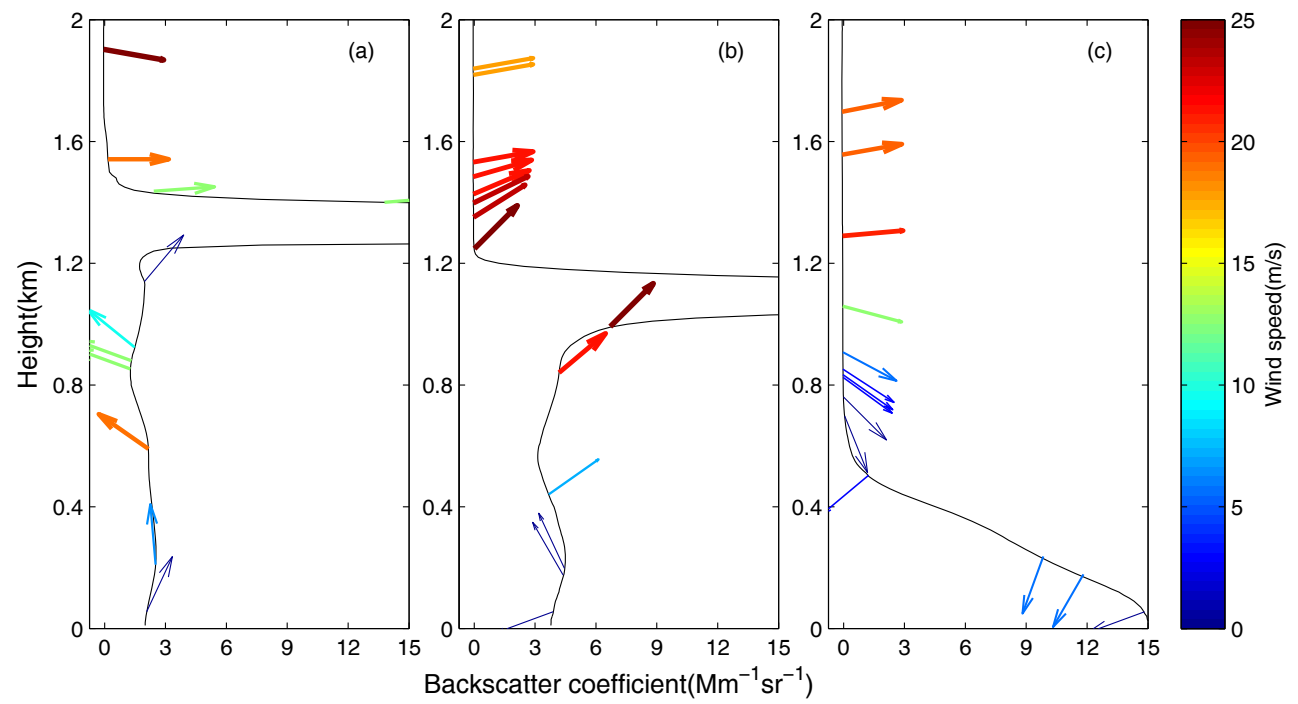

Figure 10. Attenuated backscattering coefficients and wind vectors for the period 21-26 October at (a) 08:00 LT on 21 October, (b) 08:00 LT on 22 October, and (c) 08:00 LT on 25 October.

as expected. Instead, the near-surface attenuated backscattering coefficient decreased. Thus, during the DAPEC polluted period, the decreased local contribution magnitude of pollutants was insufficient to maintain the increases of pollutant concentrations near the surface, which resulted in a zigzag distribution of atmospheric attenuated backscattering coefficients during the polluted period.

Based on the above discussion, southerly flow occurred during the transition periods (21-22 October, 7-8 November, 17-18 November) in the upper boundary layer (300 to $900 \mathrm{~m}$ ), and it transported large quantities of pollutants from the south to Beijing. In turn, the attenuated backscattering coefficients from near the surface to the upper boundary layer increased, and the abundance of pollutants in the mixing layer increased. Pollutants transported during the daytime are mixed with pollutants released locally by convective mixing, and pollutants transported at night remain above the mixing layer overnight and then move to near the surface through upper boundary layer convection after the development of the mixing layer. Because of the transportation effect, the variation rate of the entire profile was relatively small and resulted in increased column concentrations of pollutants throughout the mixing layer, which led to the air pollution. During the polluted periods (24-26 October, 8-11 November, and 19-21 November), southerly flow was not significant, and it was replaced by near-surface static winds and westerly and 

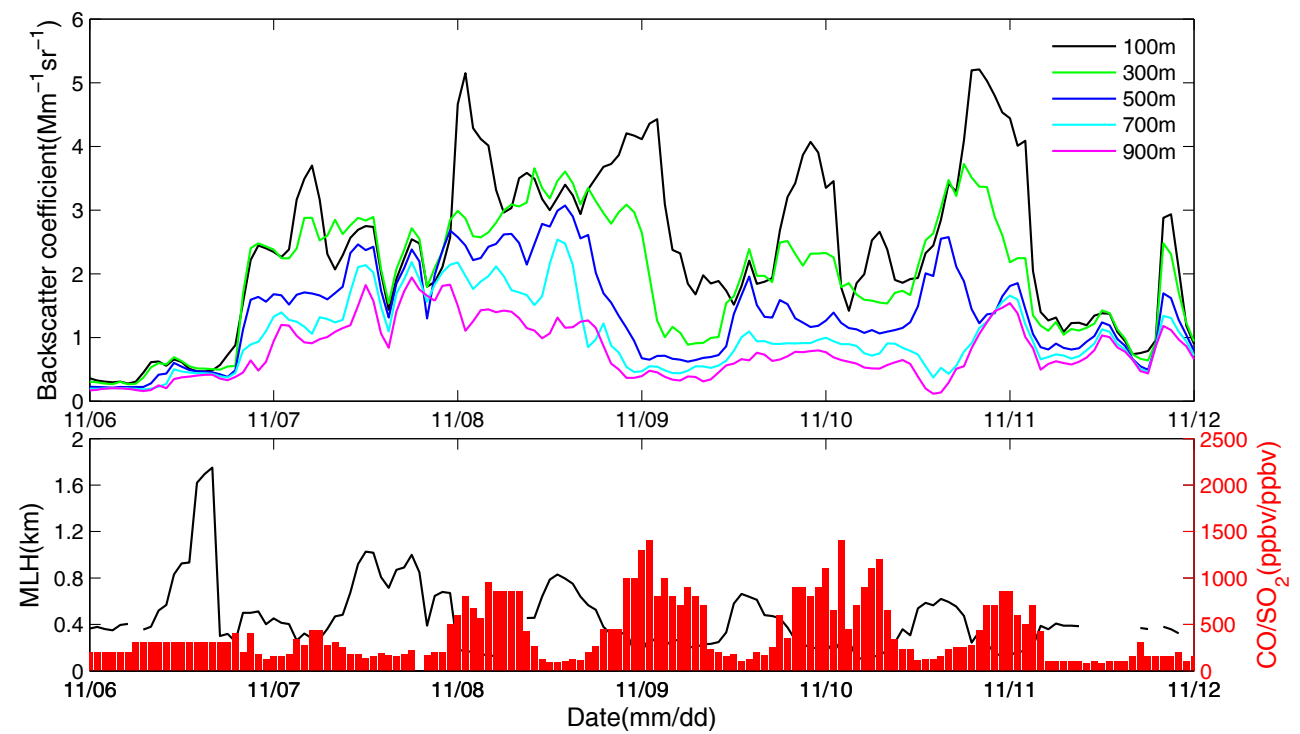

Figure 11. Attenuated backscattering coefficients at different heights and near-surface $\mathrm{CO} / \mathrm{SO}_{2}$ ratios from 6 to 11 November.
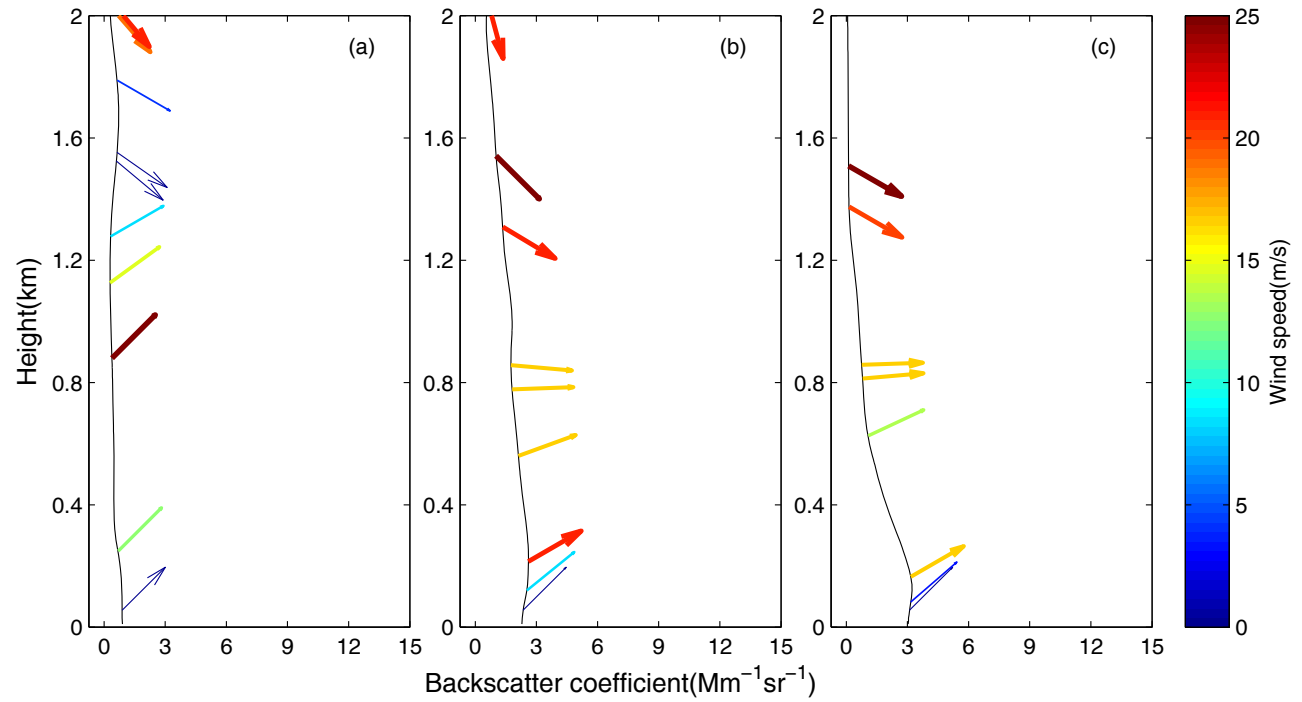

Figure 12. Attenuated backscattering coefficients and wind vectors for 6-11 November at (a) 20:00 LT on 7 November, (b) 20:00 LT on 8 November, and (c) 20:00 LT on 10 November.

northerly winds in the high layers. Because of this effect, the near-surface attenuated backscattering coefficient continued to increase, whereas that of the upper boundary layer continued to decrease, resulting in increased variation rates of the entire profile with height. The contribution of local emissions to pollution during the polluted period increased, and its contribution to the upper boundary layer was reduced.

\section{Conclusions}

The APEC summit was held in Beijing from 3 to 11 November 2014. During this period, six areas - including provinces, cities and an autonomous region - near Beijing (Beijing, Tianjin, Hebei, Shanxi, Inner Mongolia, and Shandong) worked together to control the air pollution by emission reduction, so this period provided the best experimental platform for studying regional pollution and transport. The following conclusions have been drawn based on the attenuated backscattering coefficient and mixing-layer height in the Beijing area as measured by lidar ceilometer for the period 15 October to 30 November 2014.

1. A comparison of $\mathrm{PM}_{2.5}$ concentrations and $\mathrm{AOD}$ values showed that the near-surface and $0-4500 \mathrm{~m}$ attenuated backscattering coefficient measured by the lidar 


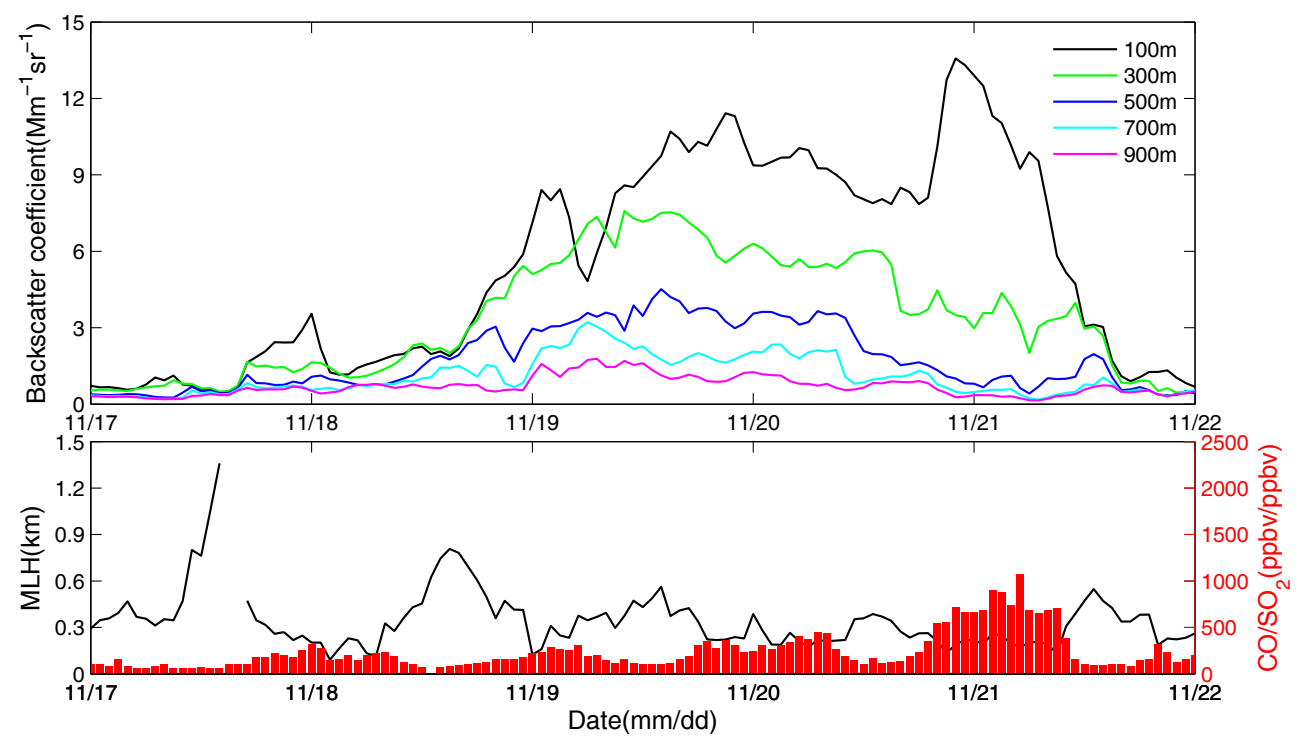

Figure 13. Attenuated backscattering coefficients at different heights and near-surface $\mathrm{CO} / \mathrm{SO}_{2}$ ratios from 17 to 21 November.
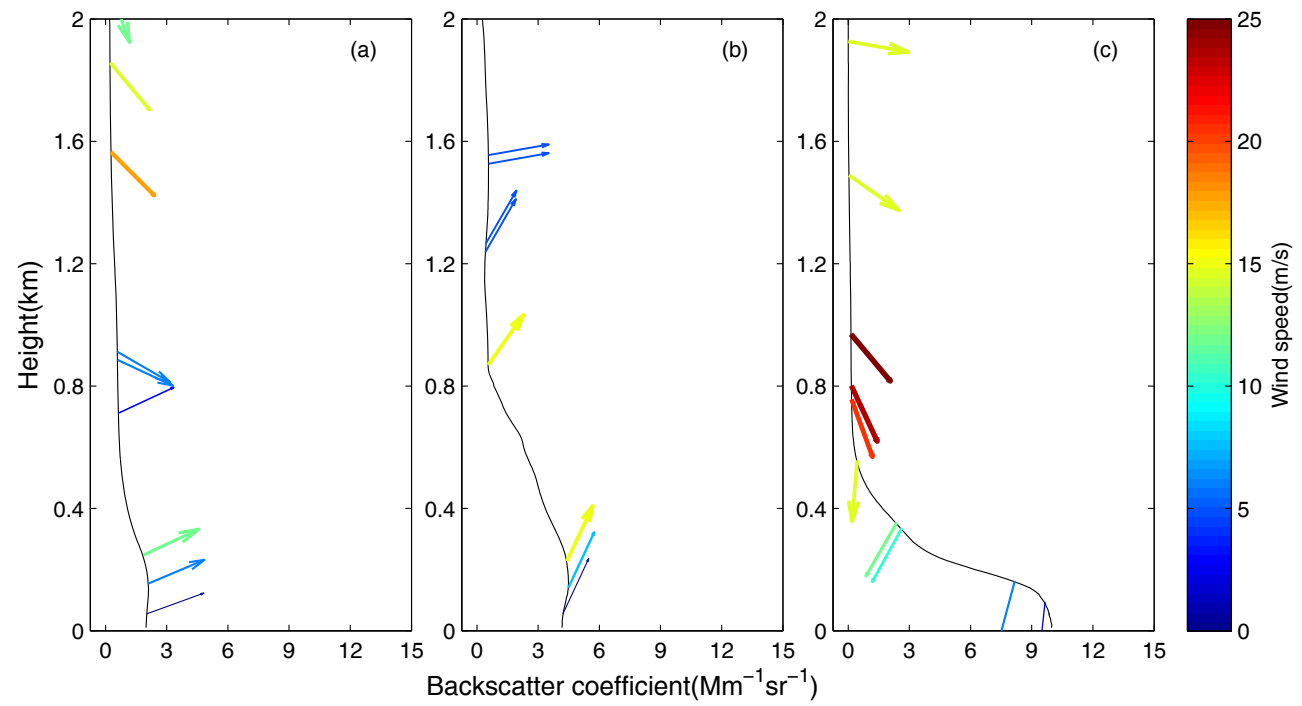

Figure 14. Attenuated backscattering coefficients and wind vectors for 17-21 November at (a) 20:00 LT on 17 November, (b) 20:00 LT on 18 November, and (c) 20:00 LT on 21 November.

ceilometer was well correlated with the near-surface $\mathrm{PM}_{2.5}$ and AOD values, respectively, indicating that the lidar ceilometer can be used to study air pollution and indicate regional transport characteristics of atmospheric aerosols in the boundary layer.

2. Air pollutants under different conditions of pollution in Beijing were from different sources. The transition period was primarily affected by southerly flow, and pollutant transport in the space from 300 to $900 \mathrm{~m}$ was significant, which resulted in the accumulation of pollutants and air pollution in Beijing. However, during the polluted period, the contribution of upper-air transport is decreased, and local contributions played an important role.

3. $\mathrm{PM}_{2.5}$ concentrations in DAPEC in Beijing were affected by coordinated regional emission reductions and decreased by approximately $60 \%$, and the visibility was enhanced by approximately $60 \%$. During the transition period, the concentration was mainly affected by regional transport, and the contribution of regional transport to aerosols in the Beijing area was decreased by 36 and $25 \%$ compared to BAPEC and AAPEC, respectively. During the polluted period, the concentration was dominated by local contributions, and the local con- 
tribution in Beijing was significantly decreased by 48 and $54 \%$ relative to BAPEC and AAPEC, respectively. A comparison of the near-surface attenuated backscattering coefficients in BAPEC and AAPEC showed that the contribution of coal burning for heating to air pollution during the polluted period was approximately $10 \%$.

Therefore, local emissions are the key factors determining the formation and development of air pollution in the Beijing area, and a reduction in local emissions can greatly decrease local pollution. However, regional transport can promote air pollution, so such processes cannot be ignored, particularly during the transition period, which results in enhanced intensity and increased accumulation of local pollution. Thus, during the transition period, emissions in areas surrounding Beijing should be reduced to effectively control regional transport and reduce the load of regional pollution. During the polluted period, local emissions should be reduced to control pollution. Our results can provide a scientific basis for emission control and management and air pollution forecasting and prevention, and they have the potential for use in the design and implementation of coordinated regional reduction strategies.

Acknowledgements. This work was supported by the CAS Strategic Priority Research Program Grant (no. XDB05020000 and XDA05100100), the Haze Observation Project Especially for Jing-Jin-Ji Area (HOPE-J ${ }^{3}$ A) (no. KJZD-EW-TZ-G06-01-04) and the National Natural Science Foundation of China (nos. 41230642 and 41222033).

Edited by: H. Saathoff

\section{References}

Auger, F., Gendron M.-C., Chamot, C., Marano, F., and Dazy A.-C.: Responses of well-differentiated nasal epithelial cells exposed to particles: role of the epithelium in airway inflammation, Toxicol. Appl. Pharm., 215, 285-294, 2006.

Campbell, A., Oldham, M., Becaria, A., Bondy, S. C., Meacher, D., Sioutas, C., Misra, C. Mendez L. B., and Kleinman, M.: Particulate matter in polluted air may increase biomarkers of inflammation in mouse brain, NeuroToxicology, 26, 133-140, 2005

Cao, X., Wang, Z., Tian, P., Wang, J., Zhang, L., and Quan, X.: Statistics of aerosol extinction coefficient profiles and optical depth using lidar measurement over Lanzhou, China since 20052008, J. Quant. Spectrosc. Ra., 122, 150-154, 2013.

Ding, G. A., Chen, C. Y., Gao, Z. Q., Yao, W. Q., Li, Y., Cheng, X. H., Meng, Z. Y., Yu, H. Q., Wong, K. H., Wang, S. F., and Miao, Q. J.: Vertical structures of $\mathrm{PM}_{10}$ and $\mathrm{PM}_{2.5}$ and their dynamical character in low atmosphere in Beijing urban areas, Sci. China Ser. D-Earth Sci., 35, 31-44, 2005.

Emeis, S., Forkel, R., Junkermann, W., Schäfer, K., Flentje, H., Gilge, S., Fricke, W., Wiegner, M., Freudenthaler, V., Groß, S., Ries, L., Meinhardt, F., Birmili, W., Münkel, C., Obleitner, F., and Suppan, P.: Measurement and simulation of the 16/17
April 2010 Eyjafjallajökull volcanic ash layer dispersion in the northern Alpine region, Atmos. Chem. Phys., 11, 2689-2701, doi:10.5194/acp-11-2689-2011, 2011.

Emeis, S., Schäfer, K., Münkel, C., Friedl, R., and Suppan, P.: Evaluation of the interpretation of ceilometer data with RASS and radiosonde data, Bound.-Lay. Meteorol., 143, 25-35, 2012.

Englert, N.: Fine particles and human health-a review of epidemiological studies, Toxicol. Lett., 149, 235-242, 2004.

Guinot, B., Roger, J.-C., Cachier, H., Wang, P., Bai, J., and Yu, T.: Impact of vertical atmospheric structure on Beijing aerosol distribution, Atmos. Environ., 40, 5167-5180, 2006.

Hänel, A., Baars, H., Althausen, D., Ansmann, A., Engelmann, R., and Sun, J. Y.: One-year aerosol profiling with EUCAARI Raman lidar at Shangdianzi GAW station: Beijing plume and seasonal variations, J. Geophys. Res., 117, D13201, doi:10.1029/2012JD017577, 2012.

IPCC: Cimate Change 2007: Synthesis Report, Contribution of Working Groups I, II and III to the Fourth Assessment Report of the Intergovernmental Panel on Climate Change Geneva, IPCC, Switzerland, 2007.

Jia, Y., Rahn, K. A., He, K., Wen, T., and Wang, Y.: A novel technique for quantifying the regional component of urban aerosol solely from its sawtooth cycles, J. Geophys. Res., 113, D21309, doi:10.1029/2008JD010389, 2008.

Jin, Y., Kai, K., Kawai, K., Nagai, T., Sakai, T., Yamazaki, A., Uchiyama, A., Batdorj, D., Sugimoto, N., and Nishizawa, T.: Ceilometer calibration for retrieval of aerosol optical properties, J. Quant. Spectrosc. Ra., 153, 49-56, 2015.

Kamp, D., McKendry, I. G., Wong, M., and Stull, R.: Lidar ceilometer observations and modeling of a fireworks plume in Vancouver, British Columbia, Atmos. Environ., 42, 7174-7178, 2008.

Liu, J., Zheng, Y., Li, Z., Flynn, C., and Cribb, M.: Seasonal variations of aerosol optical properties, vertical distribution and associated radiative effects in the Yangtze Delta region of China, J. Geophys. Res., 117, D00K38, doi:10.1029/2011JD016490, 2012.

Lu, Z., Streets, D. G., Zhang, Q., Wang, S., Carmichael, G. R., Cheng, Y. F., Wei, C., Chin, M., Diehl, T., and Tan, Q.: Sulfur dioxide emissions in China and sulfur trends in East Asia since 2000, Atmos. Chem. Phys., 10, 6311-6331, doi:10.5194/acp-106311-2010, 2010.

McAuliffe, M. A. P. and Ruth, A. A.: Typical tropospheric aerosol backscatter profiles for Southern Ireland: the Cork Raman lidar, Atmos. Res., 120-121, 334-342, 2013.

McKendry, I. G., Kamp, D., Strawbridge, K. B., Christen, A., and Crawford, B.: Simultaneous observations of boundary-layer aerosol layers with CL31 ceilometer and 1064/532 nm lidar, Atmos. Environ., 43, 5847-5852, 2009.

Münkel, C., Eresmaa, N., Räsänen, J., and Karppinen, A.: Retrieval of mixing height and dust concentration with lidar ceilometers, Bound.-Lay. Meteorol., 124, 117-128, 2007.

Myhre, G., Myhre, A., and Stordal, F.: Historical evolution of radiative forcing of climate, Atmos. Environ., 35, 2361-2373, 2001.

National Bureau of Statistics of China: China Statistical Yearbook 2014, available at: http://www.stats.gov.cn/tjsj/ndsj/2014/ indexch.htm (last access: 16 January 2015), China Statistics Press, Beijing, 2014.

Noh, Y. M., Kim, Y. J., Choi, B. C., and Murayama, T.: Aerosol lidar ratio characteristics measured bya multi-wavelength Raman 
lidar system at Anmyeon Island, Korea, Atmos. Res., 86, 76-87, doi:10.1016/j.atmosres.2007.03.006, 2007.

Pandolfi, M., Martucci, G., Querol, X., Alastuey, A., Wilsenack, F., Frey, S., O'Dowd, C. D., and Dall'Osto, M.: Continuous atmospheric boundary layer observations in the coastal urban area of Barcelona during SAPUSS, Atmos. Chem. Phys., 13, 49834996, doi:10.5194/acp-13-4983-2013, 2013.

Peters, A.: Particulate matter and heart disease: evidence from epidemiological studies, Toxicol. Appl. Pharm., 207, 477-482, 2005.

Scarino, A. J., Obland, M. D., Fast, J. D., Burton, S. P., Ferrare, R. A., Hostetler, C. A., Berg, L. K., Lefer, B., Haman, C., Hair, J. W., Rogers, R. R., Butler, C., Cook, A. L., and Harper, D. B.: Comparison of mixed layer heights from airborne high spectral resolution lidar, ground-based measurements, and the WRFChem model during CalNex and CARES, Atmos. Chem. Phys., 14, 5547-5560, doi:10.5194/acp-14-5547-2014, 2014.

Schween, J. H., Hirsikko, A., Löhnert, U., and Crewell, S.: Mixinglayer height retrieval with ceilometer and Doppler lidar: from case studies to long-term assessment, Atmos. Meas. Tech., 7, 3685-3704, doi:10.5194/amt-7-3685-2014, 2014.

Seinfeld, J. H. and Pandis, S. N.: Atmospheric Chemistry and Physics, From Air Pollution to Climate Changes, Wiley, New York, USA, 1326 pp., 1998.

Shine, K. P. and Forster P. M. D.: The effect of human activity on radiative forcing of climate change: a review of recent developments, Global Planet. Change, 20, 205-225, 1999.

Sicard, M., Pérez, C., Rocadenbosch, F., Baldasano, J. M., and Garcia-Vizcaino, D.: Mixed-layer depth determination in the Barcelona coastal area from regular lidar measurements: methods, results and limitations, Bound.-Lay. Meteorol., 119, 135157,2006

State Council: Air Pollution Prevention and Control Action Plan, China Clean Air Updates, no. GUOFA[2013]37, 2013.

Sun, Y., Song, T., Tang, G., and Wang, Y.: The vertical distribution of $\mathrm{PM}_{2.5}$ and boundary-layer structure during summer haze in Beijing, Atmos. Environ., 74, 413-421, 2013.
Tesche, M., Ansmann, A., Müller, D., Althausen, D., Engelmann, R., Hu, M., and Zhang, Y.: Particle backscatter, extinction, and lidar ratio profiling with Raman lidar in south and north China, Appl. Optics, 46, 6302-6308, 2007.

Wiegner, M. and Gasteiger, J.: Correction of water vapor absorption for aerosol remote sensing with ceilometers, Atmos. Meas. Tech., 8, 3971-3984, doi:10.5194/amt-8-3971-2015, 2015.

Wiegner, M., Madonna, F., Binietoglou, I., Forkel, R., Gasteiger, J., Geiß, A., Pappalardo, G., Schäfer, K., and Thomas, W.: What is the benefit of ceilometers for aerosol remote sensing? An answer from EARLINET, Atmos. Meas. Tech., 7, 1979-1997, doi:10.5194/amt-7-1979-2014, 2014.

Wu, Q. Z., Wang, Z. F., Gbaguidi, A., Gao, C., Li, L. N., and Wang, W.: A numerical study of contributions to air pollution in Beijing during CAREBeijing-2006, Atmos. Chem. Phys., 11, 59976011, doi:10.5194/acp-11-5997-2011, 2011.

Wu, Y., Cordero, L., Gross, B., Moshary, F., and Ahmed, S.: Assessment of CALIPSO attenuated backscatter and aerosol retrievals with a combined ground-based multi-wavelength lidar and sunphotometer measurement, Atmos. Environ., 84, 44-53, 2014.

Xin, J., Wang, Y., Tang, G., Wang, L., Sun, Y., Wang, Y. H., Hu, B., Song, T., Ji, D. S., Wang, W. F., Li, L., and Liu, G. R.: Variability and reduction of atmospheric pollutants in Beijing and its surrounding area during the Beijing 2008 Olympic Games, Chinese Sci. Bull., 55, 1937-1944, 2010.

Yang, D. W., Li, C., Lau, A. K.-H., and Li, Y.: Long-term measurement of daytime atmospheric mixing layer height over Hong Kong, J. Geophys. Res. Atmos., 118, 2422-2433, 2013.

Zhang, Q., Zhao, C., Tie, X., Wei, Q., Huang, M., Li, G., Ying, Z., and $\mathrm{Li}, \mathrm{C} .:$ Characterizations of aerosols over the Beijing region: a case study of aircraft measurements, Atmos. Environ. 40, 4513-4527, 2006.

Zhang, Q., Ma, X., Tie, X., Huang, M., and Zhao, C.: Vertical distributions of aerosols under different weather conditions: analysis of in-situ aircraft measurements in Beijing, China, Atmos. Environ., 43, 5526-5535, 2009. 